\title{
CUP CONTAINMENT AND ORIENTATION IN CEMENTED TOTAL HIP ARTHROPLASTIES
}

\author{
AUGUSTO SARMIENTO, EDWARD EBRAMZADEH, WILlIAM J. GOGAN, HARRY A. MCKELLOP
}

\author{
From the University of Southern California
}

\begin{abstract}
We reviewed the radiographs of 864 Charnley and STH (Zimmer) cemented total hip arthroplasties with a mean follow-up of seven years (maximum 16 years). Survivorship analysis was used to assess the correlation between radiographic performance and the bony containment or the coronal orientation of the acetabular cup.

The cup orientation and containment were interrelated; all vertically oriented cups were completely contained, whereas $25 \%$ of more horizontal cups were only partially contained. Completely contained cups had significantly lower incidences of complete cement-bone radiolucency $(p=0.02)$ and of wear $(p=0.09)$. Vertically oriented cups had a lower incidence of continuous radiolucency than neutrally oriented cups, but this was not statistically significant $(p=0.25)$. Our results confirm the importance of complete bony containment, and also indicate that it is better to accept vertical orientation and obtain full bony coverage than to have a more horizontal orientation with partial containment.
\end{abstract}

The importance of containment and orientation on the long-term success of the acetabular cup of a cemented total hip replacement has been extensively discussed. It is generally accepted that complete containment of the cup is desirable, but orientations to the horizontal varying from $30^{\circ}$ to as high as $50^{\circ}$ have been recommended. Furthermore, acetabular dysplasia or deficiency may require that the cup be placed in a relatively vertical plane to increase the containment.

We have applied survivorship analysis to the radiographic results of a large series of cemented total hip replacements to assess the effect of bony coverage and of orientation on the long-term durability of the acetabular components.

\section{MATERIALS AND METHODS}

From 1970 to 1975 , we used the Charnley design, and from 1975 to 1980 the STH design (both from Zimmer

\footnotetext{
A. Sarmiento, MD, Professor and Chairman

E. Ebramzadeh, MS, Instructor of Research Orthopaedics

W. J. Gogan, MD, Reconstructive Fellow

H. A. McKellop, PhD, Assistant Professor of Research Orthopaedics Department of Orthopaedics, University of Southern California, School of Medicine, 2300 South Flower Street, Suite 202, Los Angeles, California 90007 , USA.

Correspondence should be sent to Professor A. Sarmiento.

(C) 1990 British Editorial Society of Bone and Joint Surgery $0301-620 X / 90 / 6028 \$ 2.00$

J Bone Joint Surg [Br] 1990; 72-B: 996-1002.
}

Inc, Warsaw, Indiana, USA). The Charnley femoral component was of cold worked $316 \mathrm{LVM}$ stainless steel (modulus of elasticity $200 \mathrm{GPa}$ ), whereas the STH stems were of titanium-aluminium-vanadium alloy (Ti-6Al4V, ASTM F136, modulus of elasticity $100 \mathrm{GPa}$ ). The Charnley prosthesis had a $22 \mathrm{~mm}$ diameter head, com-

Table I. Details of patients by prosthesis used in 864 primary THRs (number and percentage of total series)

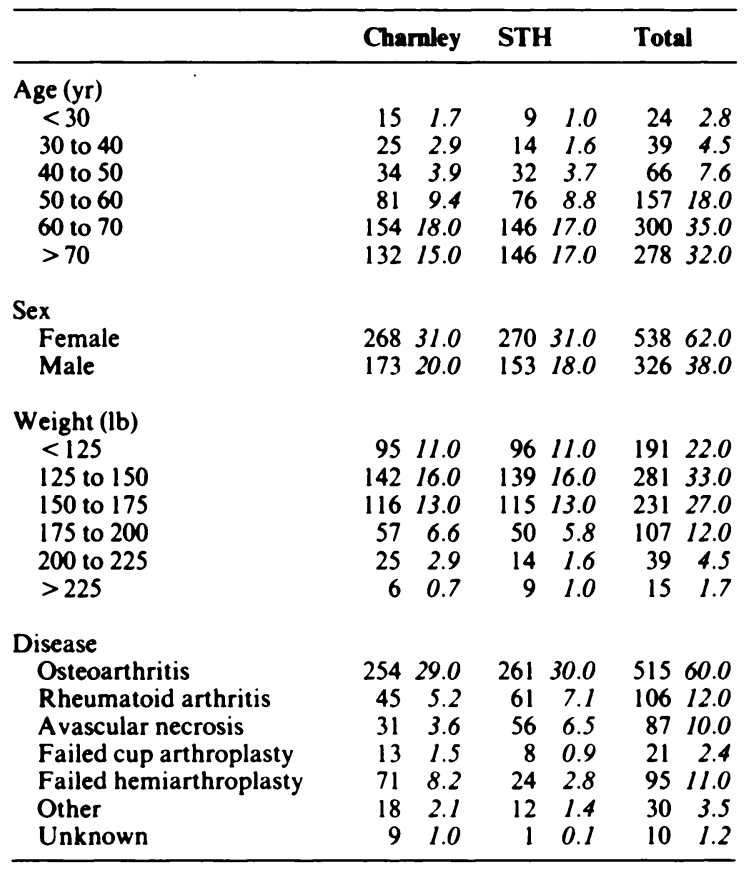


Table II. Orientation versus containment of acetabular cups, with a breakdown of disease in each category

\begin{tabular}{|c|c|c|c|c|}
\hline \multirow[b]{3}{*}{ Orientation } & & \multicolumn{3}{|c|}{ Containment } \\
\hline & & \multirow{2}{*}{$\begin{array}{l}\text { Complete } \\
100 \%\end{array}$} & \multicolumn{2}{|l|}{ Partial } \\
\hline & & & $99 \%$ to $90 \%$ & $90 \%$ to $75 \%$ \\
\hline $\begin{array}{l}\text { Horizontal }<35^{\circ} \text { (number) } \\
\text { Percentage with: }\end{array}$ & $\begin{array}{l}\text { OA } \\
\text { RA } \\
\text { AVN } \\
\text { Failed cup } \\
\text { Failed hemiarthroplasty } \\
\text { Other }\end{array}$ & $\begin{array}{r}30 \\
63 \\
17 \\
0 \\
3 \\
7 \\
10\end{array}$ & $\begin{array}{r}10 \\
40 \\
20 \\
10 \\
0 \\
30 \\
0\end{array}$ & $\begin{array}{l}0 \\
- \\
- \\
- \\
- \\
-\end{array}$ \\
\hline $\begin{array}{l}\text { Neutral } 45^{\circ} \pm 10^{\circ} \text { (number) } \\
\text { Percentage with: }\end{array}$ & $\begin{array}{l}\text { OA } \\
\text { RA } \\
\text { AVN } \\
\text { Failed cup } \\
\text { Failed hemiarthroplasty } \\
\text { Other }\end{array}$ & $\begin{array}{r}688 \\
57 \\
13 \\
11 \\
3 \\
13 \\
4\end{array}$ & $\begin{array}{r}76 \\
70 \\
11 \\
9 \\
3 \\
4 \\
4\end{array}$ & $\begin{array}{r}9 \\
78 \\
0 \\
11 \\
0 \\
11 \\
0\end{array}$ \\
\hline $\begin{array}{l}\text { Vertical }>55^{\circ} \text { (number) } \\
\text { Percentage with: }\end{array}$ & $\begin{array}{l}\text { OA } \\
\text { RA } \\
\text { AVN } \\
\text { Failed cup } \\
\text { Failed hemiarthroplasty } \\
\text { Other }\end{array}$ & $\begin{array}{r}51 \\
76 \\
10 \\
6 \\
2 \\
0 \\
6\end{array}$ & $\begin{array}{l}0 \\
- \\
- \\
- \\
- \\
- \\
-\end{array}$ & $\begin{array}{l}0 \\
- \\
- \\
- \\
- \\
- \\
-\end{array}$ \\
\hline
\end{tabular}
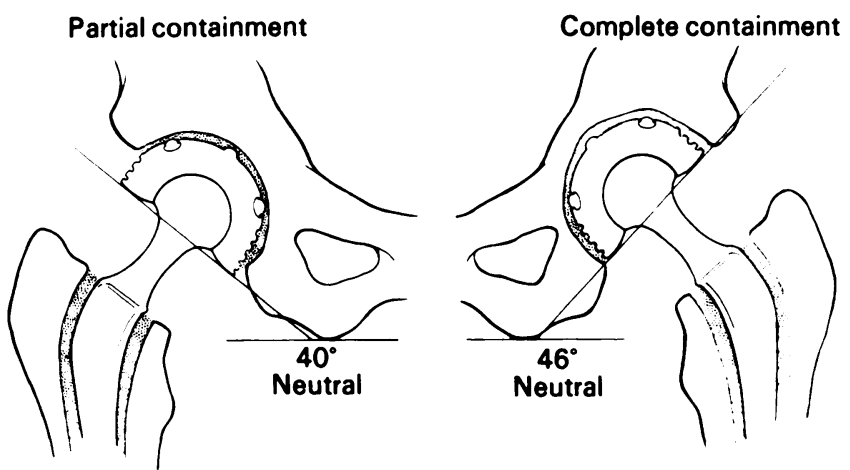

Fig. 1

Diagram to show the method of measuring the orientation and containment of the acetabular cup.

pared to $28 \mathrm{~mm}$ for the STH. The neck-shaft angles of the components were Charnley $128^{\circ}$, STH $134^{\circ}$.

The acetabular cups for both prostheses were of ultra-high molecular weight (UHMW) polyethylene and had similar geometries, except in respect of their internal diameters. No metal-backed acetabular components were used.

Of a total of 973 hip replacements, we excluded 20 which developed early infection, 42 which were revisions for failure of a previous cemented arthroplasty, and 47 for which data were incomplete. The mean follow-up for the remaining 864 primary replacements was 6.9 years. The 441 Charnley prostheses had a mean follow-up of 7.7 years (maximum 16), and the 423 STH prostheses had a mean follow-up of 6.1 years (maximum 11). The Charnley and STH groups were similar with respect to age, sex, weight and underlying disease (Table I).
The Charnley prostheses were inserted by a lateral approach, with trochanteric osteotomy, and the STH prostheses by a posterior approach, without trochanteric osteotomy. In no cases did we use special cementing techniques such as intramedullary plugs, vent tubes, brushing, pulsating lavage of the reamed osseous surfaces and pressurisation.

All the acetabular cups in both groups were implanted using Charnley's (1961) original technique. Every effort was made to place them so that they were completely contained by bone and cement and inclined at $45^{\circ}$ to the horizontal (Charnley 1972), but this was not always accomplished.

Anteroposterior radiographs of each hip were obtained immediately before operation and postoperatively, at approximately three, six and 12 weeks, six months and then annually whenever possible. The serial radiographs were evaluated, with no knowledge of the clinical status of the patients, by one experienced observer or by observers well-instructed in the appropriate criteria (Gruen, McNeice and Amstutz 1979; Sarmiento and Gruen 1985; Sarmiento et al 1988).

The hips we reviewed were divided into groups based on the amount of containment of the cup in the acetabulum and the horizontal orientation of the cup (Table II). Containment by bone was recorded as $100 \%$, $90 \%$ to $99 \%, 75 \%$ to $90 \%$, or less than $75 \%$. Orientation was recorded as the angle between a line connecting the ischial spines and a line tangential to the opening of the cup (Fig. 1). It has been shown that this angle can be measured accurately even with different positions of the pelvis in relation to the X-ray beam (Sellers, Lyles and Dorr 1988). Angles of $45^{\circ} \pm 10^{\circ}$ were classified as 
'neutral', greater than $55^{\circ}$ as 'vertical', and less than $35^{\circ}$ as 'horizontal'.

No cups had less than $75 \%$ bony coverage, and all the vertical cups were $100 \%$ contained. Of the more horizontal cups, $25 \%$ had less than $100 \%$ bony coverage (Table II). This correlation has previously been documented (Djerf, Wahlström and Hammerby 1986). Table III summarises the containment and orientation for each type of prosthesis. The containment and orientation subgroups were found to be similar with respect to the underlying disease (Table II).

For the long-term evaluation of loosening we considered the acetabulum in three zones (DeLee and Charnley 1976) and the proximal femur in seven zones (Gruen et al 1979). The serial radiographs were then evaluated for eight factors that are generally accepted as indicating the long-term performance of cemented arthroplasties (Tables IV and V).

Table III. Orientation and containment by number for each type of prosthesis

\begin{tabular}{lrrr}
\hline & Charnley & STH & Total \\
\hline Orientation & & & \\
$\quad$ Horizontal $<35^{\circ}$ & 21 & 19 & 40 \\
Neutral $45^{\circ} \pm 10^{\circ}$ & 416 & 357 & 773 \\
Vertical $>55^{\circ}$ & 4 & 47 & 51 \\
Containment & & & \\
Complete & 363 & 406 & 769 \\
Partial & 78 & 17 & 95 \\
\hline
\end{tabular}

Table IV. Survival rates at 12 years related to containment by percentage of group. Beyond 12 years, fewer than 10 hips were followed in the smaller group, yielding unreliable survival rates

\begin{tabular}{lll}
\hline & \multicolumn{2}{l}{ Containment } \\
\cline { 2 - 3 } Factors assessed & $\begin{array}{l}\text { Complete } \\
(\mathbf{n}=\mathbf{7 6 9 )}\end{array}$ & $\begin{array}{l}\text { Partial } \\
(\mathbf{n}=\mathbf{9 5})\end{array}$ \\
\hline Acetabular cup & & \\
$\quad$ No continuous radiolucency & 70 & 57 \\
No acetabular wear & 71 & 63 \\
Femoral stem & & \\
$\quad$ No progressive loosening & 86 & 91 \\
No bone-cement radiolucency & 45 & 47 \\
No stem-cement radiolucency & 77 & 87 \\
No cement fracture & 91 & 91 \\
No calcar resorption & 39 & 43 \\
No cortical hypertrophy & 75 & 65 \\
\hline
\end{tabular}

We then used survival analysis to calculate the probability of the occurrence of each of these eight performance factors over the duration of the study (Gehan 1969). Survival analysis allows not only the frequency of occurrence of each factor to be considered, but, more importantly, the time at which it occurs. This technique allowed us to use data from all of the patients, despite varying lengths of follow-up.
The probability level $p<0.05$ is commonly chosen to indicate statistical significance, but we have discussed differences with a significance level of $p \leq 0.15$, allowing the reader to assess the relative significance of the various results.

We computed survivorship functions for coverage, and for orientation angle for both types of prosthesis. Table IV gives the end-point percentages for acetabular containment and Table $\mathrm{V}$ those for orientation at the longest possible follow-up, when 10 hips were still available for assessment. With smaller numbers than this, the loss of a single hip induces an unrealistically large shift in the survivorship function (Dorey and Amstutz 1986).

\section{RESULTS}

Only nine hips showed less than $90 \%$ containment (Table II) and, probably due to the small number, we found no significant differences between these and cups with $90 \%$ to $99 \%$ containment. We therefore combined all cups with less than $100 \%$ bony coverage into one category and referred to them as having 'partial' containment.

Table V. Survival rates at eight years related to orientation by percentage of group, thus excluding comparison where there were fewer than 10 hips in the smallest group

\begin{tabular}{|c|c|c|c|}
\hline \multirow[b]{2}{*}{ Factor assessed } & \multicolumn{3}{|l|}{ Orientation } \\
\hline & $\begin{array}{l}\text { Horizontal } \\
<35^{\circ} \\
(n=40)\end{array}$ & $\begin{array}{l}\text { Neutral } \\
45^{\circ} \pm 10^{\circ} \\
(n=773)\end{array}$ & $\begin{array}{l}\text { Vertical } \\
>55^{\circ} \\
(n=51)\end{array}$ \\
\hline \multicolumn{4}{|l|}{ Acetabular cup } \\
\hline No continuous radiolucency & 86 & 87 & 94 \\
\hline No acetabular wear & 93 & 93 & 100 \\
\hline \multicolumn{4}{|l|}{ Femoral stem } \\
\hline No progressive loosening & 82 & 91 & 91 \\
\hline No bone-cement radiolucency & 48 & 62 & 44 \\
\hline No stem-cement radiolucency & 80 & 88 & 91 \\
\hline No cement fracture & 92 & 95 & 91 \\
\hline No calcar resorption & 76 & 75 & 70 \\
\hline No cortical hypertrophy & 97 & 90 & 95 \\
\hline
\end{tabular}

Acetabular performance. For all acetabular cups, regardless of orientation, completely contained cups had lower incidences of bone-cement radiolucency $(p=0.023$, Fig. 2 ) and of wear ( $p=0.09$, Fig. 3) than partially contained cups. No vertically oriented cups had partial containment, but for neutral and horizontal cups as separate subgroups, complete containment was associated with lower incidences of continuous radiolucency than partial containment $(p=0.15$ for neutral cups and $p=0.006$ for horizontal cups).

For all cups, regardless of containment, those which were vertically oriented showed a lower incidence of continuous radiolucent zones than those with neutral orientation, although the difference was not statistically 


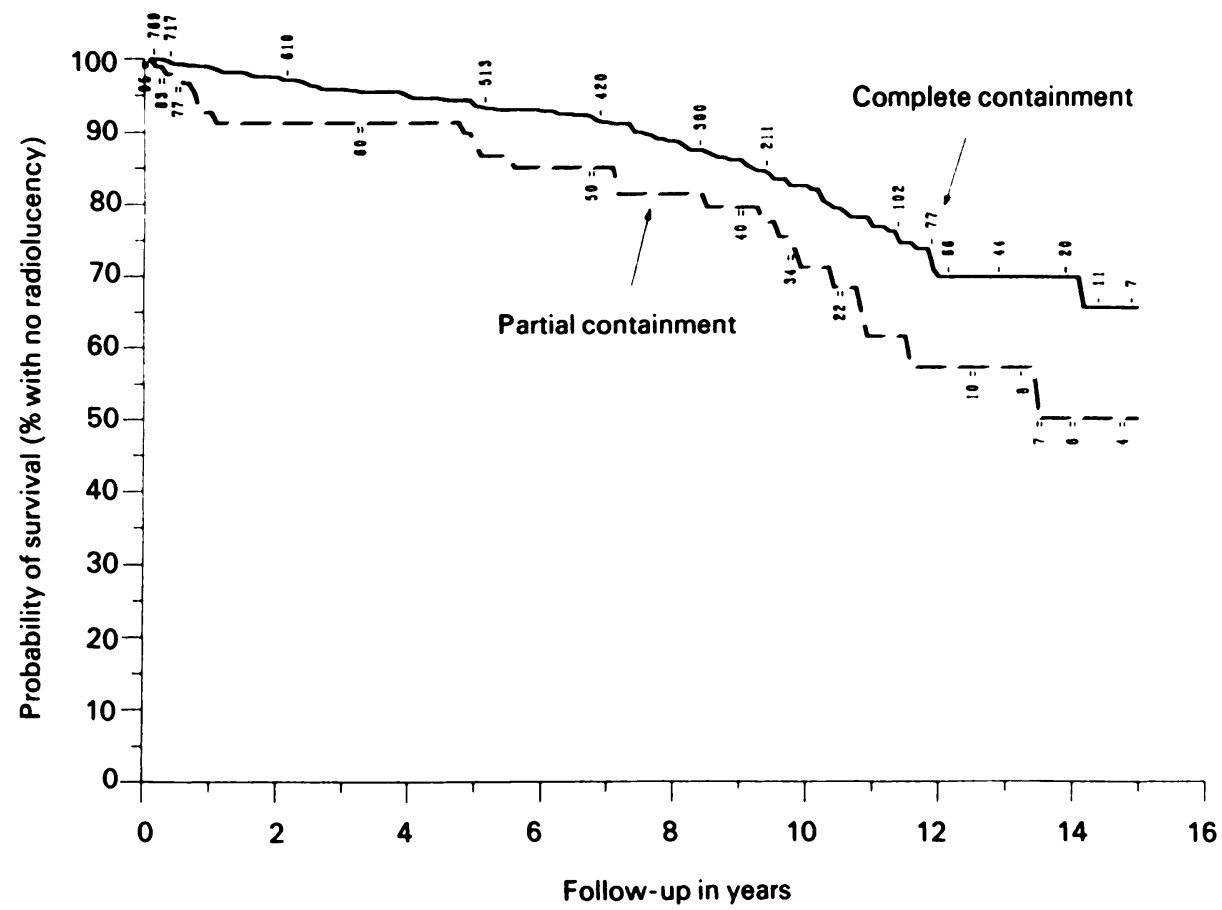

Fig. 2

Survivorship graph for the absence of radiolucent lines about the cup, comparing those with complete containment to those with partial containment. The number of THRs under review at various periods of follow-up are indicated. For example, at least 420 completely contained cups and at least 50 partially contained cups had been followed up for over 6.5 years.

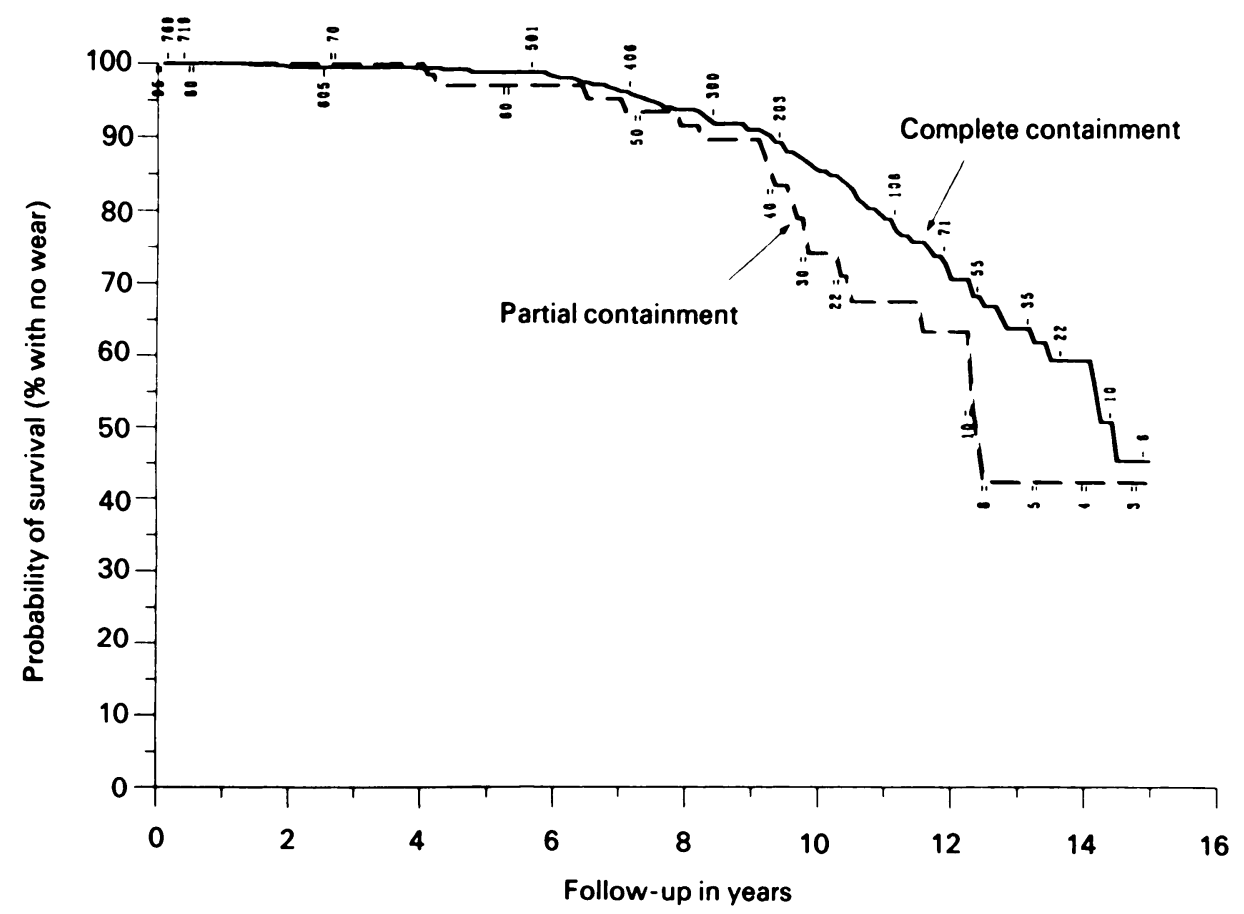

Fig. 3

Survivorship graph for absence of wear of the acetabular cup comparing those with complete containment to those with partial containment. As in Figure 2, the number of hips being followed up is indicated at various points. 
significant ( $p=0.25$, Fig. 4). For fully covered cups there were no statistically significant differences in acetabular performance among vertical, neutral or horizontal alignment ( $p>0.25$ ). For partially contained cups, however, those which were neutrally oriented had a lower incidence of radiolucency than horizontal cups $(p=0.09)$. Cups with vertical orientation and complete containment had a lower incidence of acetabular radiolucency than neutral cups with partial containment $(\mathrm{p}<0.14)$.

When the performance of the acetabular cups was evaluated for Charnley and STH components as separate subgroups, those which were completely contained showed lower incidences of continuous radiolucency than those partially contained $(\mathrm{p}=0.04$ for Charnley, $\mathrm{p}=$ 0.014 for STH). None of the four Charnley hips with vertical orientation had acetabular radiolucency, and only one showed wear. Similarly, the STH hips with vertical orientation had a lower incidence of acetabular radiolucent zones than those with neutral orientation, although this was not statistically significant $(p=0.15)$. Femoral side. For all THRs together, regardless of cup orientation, radiographic changes in the femoral component were not significantly correlated with cup containment ( $p>0.25$ ). This was also true of hips with horizontal cups as a subgroup. Among the hips with neutrally oriented cups, however, those with partial coverage had a lower incidence of stem-cement radiolucency than those that were fully covered $(p=0.06)$.
For all hips together, regardless of coverage, the hips with neutrally oriented cups had a lower incidence of femoral bone-cement radiolucency than those with vertically oriented cups $(p=0.0002)$ and those with horizontally oriented cups ( $p=0.13)$.

Failures and dislocations. Twenty-seven hips $(3.1 \%)$ had been revised. These included 18 of Charnley type (4\%); four for failure of the femoral component, 10 for loosening of the acetabular component and four for loosening of both components. Nine STH hips $(2 \%)$ had been revised; four for failure of the femoral component, two for failure of the acetabular component and three for failure of both components. Table VI shows the distribution of revised hips with respect to orientation and containment of the acetabular cups.

Hip dislocations occurred in 11 of the neutrally orientated cups $(1.3 \%)$; no dislocations were seen with vertically or horizontally oriented cups.

\section{DISCUSSION}

With completely covered cups we found lower incidences of continuous radiolucent lines and of acetabular wear. This agrees with both clinical and laboratory data concerning the importance of maximising the bony containment of the acetabular component. Harris (1978) stated that at least $80 \%$ of the cup should be covered, and Callaghan et al (1985) recommended that no more than a $10^{\circ}$ arc of the cup should be left uncovered. Other

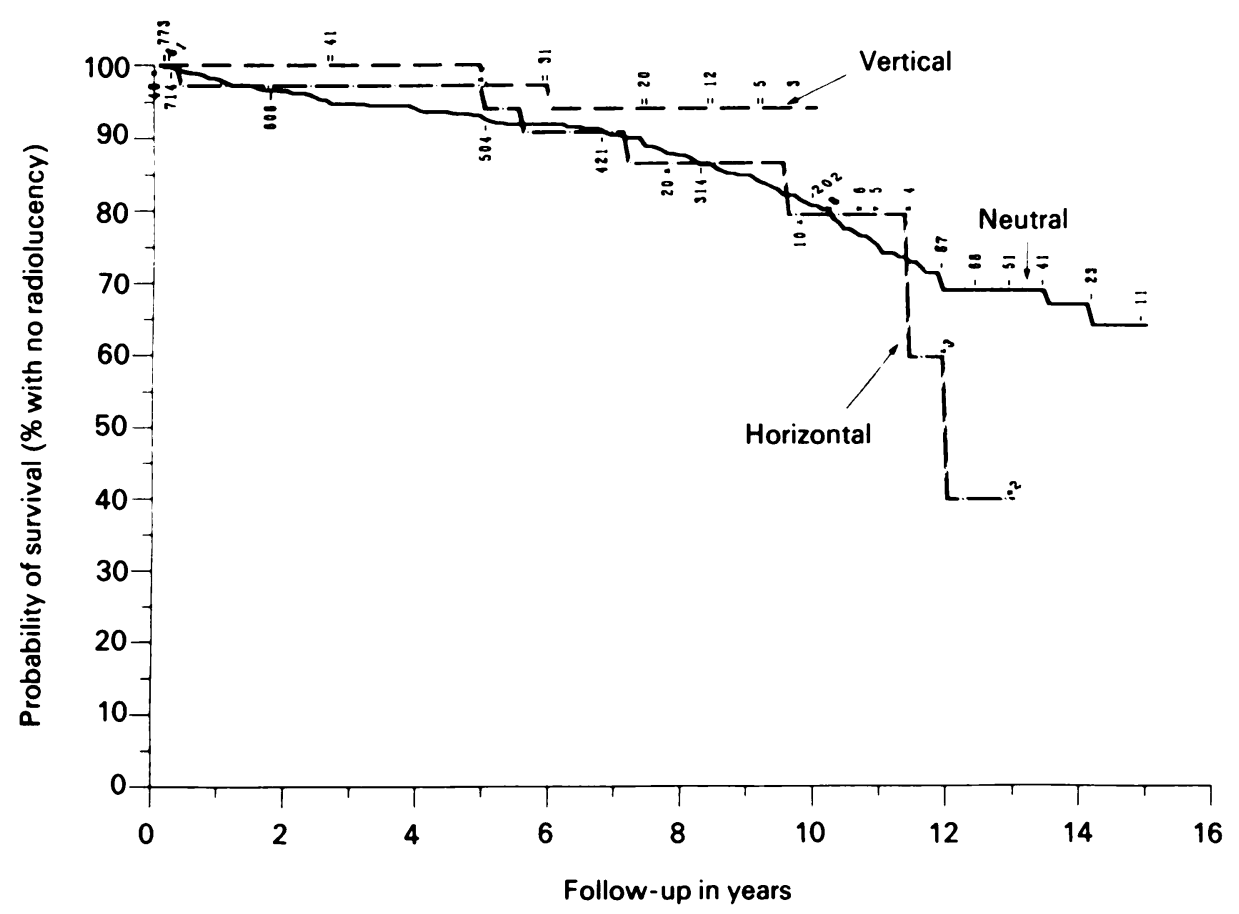

Fig. 4

Survivorship graph for absence of radiolucent lines about the cup, comparing those with vertical, neutral and horizontal orientation. The number being followed up is indicated for each group. 
Table VI. Number of hips and percentage of that category requiring revision, related to orientation and containment

\begin{tabular}{|c|c|c|c|}
\hline \multirow[b]{2}{*}{ Orientation } & \multicolumn{3}{|l|}{ Containment } \\
\hline & Complete & Partial & \\
\hline Horizontal $<35^{\circ}$ & Both components 13.3 & Acetab & 220 \\
\hline Neutral $45^{\circ} \pm 10^{\circ}$ & $\begin{array}{lrl}\text { Acetabulum } & 10 & 1.5 \\
\text { Femur } & 7 & 1 \\
\text { Both components } & 6 & 1 \\
\text { Total: } & 23 & 3.3\end{array}$ & Femur & 11 \\
\hline Vertical $>55^{\circ}$ & 0 & & 0 \\
\hline
\end{tabular}

clinical studies have associated partial containment with a higher incidence of acetabular loosening (Pellicci, Salvati and Robinson 1979; Pellicci et al 1982; Sutherland et al 1982; McBroom and Müller 1984; Morrey and Ilstrup 1989). Volz and Wilson (1977) demonstrated in a cadaver study that less torque was required to dislodge partially contained cups than those with complete containment.

It is generally agreed that full coverage should be attained whenever possible, but this cannot be achieved independently of orientation, and the optimum angle of orientation has not been defined. An angle of $45^{\circ}$ has been recommended for the Charnley cup (Charnley 1972; Coventry et al 1974; Eftekhar 1978) and for the Müller cup (Müller 1970). In contrast, Harris (1978) and McKee and Watson-Farrar (1966) recommended $30^{\circ}$ for the HD2 and the McKee-Farrar cups, respectively.

Where there is deficient acetabular bone stock, Harris and others (Harris 1978; Woolson and Harris 1983; Morrey and Ilstrup 1989) have recommended the use of a smaller component, and augmentation with bone grafts to achieve full bony coverage while maintaining neutral orientation. Bi-equatorial cups have also been advocated for this purpose (Pipino and Calderale 1987). We found that the radiographic performance of vertical cups, in both prostheses, was as good or better than that of neutral or horizontal cups. This strongly suggests that placing the cup in a vertical orientation to increase containment is safe and is a less complicated alternative.

Our good results with vertically oriented cups agree with the findings of Russotti, Coventry and Stauffer (1988) and Salvati et al (1976), who both found higher incidences of acetabular radiolucency in horizontally oriented cups. In contrast, a number of authors have reported that vertical orientation is correlated with higher incidences of calcar resorption (Hierton, Blomgren and Lindgren 1983), polyethylene wear (Copeland and Caden 1988), loosening of the acetabular component (Coudane et al 1981; Pellicci et al 1982; McBroom and Müller 1984; Callaghan et al 1985; Djerf et al 1986; Agins et al 1988), and dislocation (Lewinnek et al 1978). However, in several of these studies (Pellicci et al 1982; Callaghan et al 1985; Agins et al 1988) the conclusions were based on a relatively small number of vertical cups in a series of hips requiring revision. For example,
Callaghan et al (1985) reported that $7 \%$ of the acetabular components revised for loosening had a vertical orientation, but the orientation of the remaining $93 \%$ was not indicated.

We believe that the problem of dislocation is more likely to result from other causes such as the wrong angle of anteversion, excessive hip movement in the absence of soft-tissue scarring, severe soft-tissue imbalance, nonunion of the osteomised greater trochanter or postoperative leg-length discrepancy.

The correlation of femoral performance with two of the acetabular subgroups was probably due to secondary factors. In neutrally oriented cups, partial coverage was apparently correlated with a lower incidence of femoral stem-cement radiolucency. However, $81 \%$ of these cups were in Charnley prostheses, and we have previously reported (Sarmiento and Gruen 1985; Sarmiento et al 1988) that the Charnley prosthesis had a lower incidence of stem radiolucencies than the STH, so the apparent correlation may be due to this imbalance in types of prosthesis.

Similarly, the apparent correlation between neutrally oriented cups and fewer femoral radiolucencies may have been due to the fact that vertical orientation was much more common with the STH cup, there being only four in the Charnley group. STH femoral components show a higher incidence of femoral radiolucency.

The relatively more satisfactory performance of vertically oriented cups in our study may be due to the improved distribution of stresses in the acetabular cement and surrounding bone. Our hypothesis is that when a load on the hip results in forces directed upward and laterally, a horizontal cup is more susceptible to tilting than a vertically oriented one. This would result in dangerously high tensile stresses at the medial bonecement interface, an increased incidence of radiolucency and eventual loosening. Although experimental and mathematical modelling would be required to substantiate this hypothesis, we feel that, if a choice must be made, it is preferable to place the cup at an angle greater than $45^{\circ}$ in order to obtain full bony coverage than to leave the cup in neutral orientation but only partially contained.

This study was supported in part by the Cora Kaiser foundation of Orthopaedic Hospital in Los Angeles. The authors also wish to thank Thomas A. Gruen for his valuable contribution to this project.

No benefits in any form have been received or will be received from a commercial party related directly or indirectly to the subject of this article.

\section{REFERENCES}

Agins HJ, Alcock NW, Bansal M, et al. Metallic wear in failed titaniumalloy total hip replacements: a histological and quantitative analysis. J Bone Joint Surg [ Am] 1988; 70-A :347-56.

Callaghan JJ, Salvati EA, Pellicci PM, Wilson PD Jr, Ranawat CS. Results of revision for mechanical failure after cemented total hip replacement, 1979 to 1982: a two to five-year follow-up. J Bone Joint Surg [Am] 1985; 67-A:1074-85.

Charnley J. Arthroplasty of the hip: a new operation. Lancet 1961; i:1129-32. 
Charnley J. The long-term results of low-friction arthroplasty of the hip performed as a primary intervention. J Bone Joint Surg [Br] 1972; 54-B:61-76.

Copeland CX Jr, Caden JG. Long-term results of Charnley total hip arthroplasty. Cont Orth 1988; 16:15-8.

Coudane H, Fery A, Sommelet J, Lacoste J, Leduc P, Gaucher A. Aseptic loosening of cemented total arthroplasties of the hip in relation to positioning of the prosthesis: new utilization of the Tschuprow-Cramer statistical test. Acta Orthop Scand 1981; $52: 201-5$.

Coventry MB, Beckenbaugh RD, Nolan DR, Ilstrup DM. 2,012 total hip arthroplasties: a study of postoperative course and early complications. J Bone Joint Surg [ Am] 1974; 56-A :273-84.

DeLee JG, Charnley J. Radiological demarcation of cemented sockets in total hip replacement. Clin Orthop 1976; 121:20-32.

Djerf K, Wahlström O, Hammerby S. Loosening 5 years after total hip replacement - a radiological study of the McKee-Farrar and Charnley prostheses. Arch Orthop Trauma Surg 1986; 105:339-42.

Dorey F, Amstutz HC. Survivorship analysis in the evaluation of joint replacement. J Arthroplasty 1986; $1: 63-9$.

Eftekhar NS. Principles of total hip arthroplasty. St. Louis: CV Mosby Co, 1978.

Gehan EA. Estimating survival functions from the life table. $J$ Chron Dis $1969 ; 21: 629-44$.

Gruen TA, McNeice GM, Amstutz HC. "Modes of failure" of cemented stem-type femoral components. Clin Orthop 1979; $141: 17-27$.

Harris WH. Total hip replacement for osteoarthritis secondary to congenital dysplasia or congenital dislocation of the hip. Int Orthop (SICOT) 1978; 2:127-38.

Hierton C, Blomgren G, Lindgren U. Factors leading to rearthroplasty in a material with radiographically loose total hip prostheses. Acta Orthop Scand 1983;54:562-5.

Lewinnek GE, Lewis JL, Tarr R, Compere CL, Zimmerman JR. Dislocations after total hip-replacement arthroplasties. J Bone Joint Surg [Am] 1978;60-A :217-20.

McBroom R, Mäller M. Aseptic loosening: fifteen years' experience with the Müller total hip arthroplasty. J Bone Joint Surg [ Br] 1984; 66-B:300-1.
McKee GK, Watson-Farrar J. Replacement of arthritic hips by the McKee-Farrar prosthesis. J Bone Joint Surg [Br] 1966; 48-B 245-59.

Morrey BF, Ilstrup D. Size of the femoral head and acetabular revision in total hip-replacement arthroplasty. J Bone Joint Surg [Am] $1989 ; 71-A: 50-5$.

Mäller ME. Total hip prostheses. Clin Orthop 1970; 72:46-68.

Pellicci PM, Salvati EA, Robinson HJ. Mechanical failures in total hip replacement requiring reoperation. J Bone Joint Surg [Am] 1979; 61-A :28-36.

Pellicei PM, Wilson PD Jr, Sledge CB, Salvati EA, Ranawat CS, Poss R. Revision total hip arthroplasty. Clin Orthop 1982; 170:34-41.

Pipino F, Calderale PM. Biodynamic total hip prosthesis. Ital J Orthop Traumatol 1987; 13:289-97.

Russotti GM, Coventry MB, Stauffer RN. Cemented total hip arthroplasty with contemporary techniques: a five-year minimum follow-up study. Clin Orthop 1988; 235:141-7.

Salvati EA, Im VC, Aglietti P, Wilson PD Jr. Radiology of total hip replacements. Clin Orthop 1976; $121: 74-82$.

Sarmiento A, Gruen TA. Radiographic analysis of a low-modulus titanium-alloy femoral total hip component : two to six-year followup. J Bone Joint Surg [Am] 1985; 67-A :48-56.

Sarmiento A, Natarajan V, Gruen TA, McMahon M. Radiographic performance of two different total hip cemented arthroplasties. Orthop Clin North Am 1988; 19:505-15.

Sellers RG, Lyles D, Dorr LD. The effect of pelvic rotation on alpha and theta angles in total hip arthroplasty. Cont Orth 1988; 17:67-70.

Sutherland CJ, Wilde AH, Borden LS, Marks KE. A ten-year followup of one hundred consecutive Müller curved-stem total hipreplacement arthroplasties. J Bone Joint Surg [Am] 1982; 64-A : 970-82.

Volz RG, Wilson RJ. Factors affecting the mechanical stability of the cemented acetabular component in total hip replacement. $J$ Bone Joint Surg [ Am] 1977; 59-A :501-4.

Woolson ST, Harris WH. Complex total hip replacement for dysplastic or hypoplastic hips using miniature or microminiature components. J Bone Joint Surg [ Am] 1983; 65-A:1099-108. 